ISSN 0974-3618 (Print) 0974-360X (Online) www.rjptonline.org
ARJPT

$\underline{\text { RESEARCH ARTICLE }}$

\title{
Preferred Learning Styles of Undergraduate and Graduate Pharmacy Students
}

\author{
Tetiana M. Derkach ${ }^{1 *}$, Anna I. Kharitonenko ${ }^{2}$ \\ ${ }^{1}$ Department of Professional Education in Technologies and Design, Kyiv National University of Technologies \\ and Design, Nemirovicha-Danchenko Str, 2, Kyiv, 01011, Ukraine \\ ${ }^{2}$ Department of Industrial Pharmacy, Kyiv National University of Technologies and Design, Nemirovicha- \\ Danchenko Str, 2, Kyiv, 01011, Ukraine \\ *Corresponding Author E-mail: derkach.tm@knutd.edu.ua
}

\begin{abstract}
:
The indices of learning styles by Felder-Soloman's method have been studied for 188 students of the speciality "Industrial Pharmacy" of 1-5 years of study. The preferred learning styles for undergraduate students remain practically unchanged during four years of study and are characterised by the predominance of active (65-79\% of all respondents), sensitive (82-92\%), visual (75-81\%) and sequential (64-73\%) styles. In contrast, master's students demonstrate more adherents of the reflective (43\% graduate versus on average $29 \%$ undergraduate students), intuitive ( $29 \%$ vs $12 \%$ ) and verbal styles (43\% vs $23 \%$ ). No significant changes in the dimension of sequential-global styles are observed: $70-71 \%$ of students prefer a sequential style for all five years of study. Thus, the preferences in learning styles demonstrate stability over four years of a bachelor's course. The difference between the styles of undergraduate and graduate students is likely to emerge at a stage of the additional selection of students when they enter a master's course. The change in the learning profile of a group of master's students takes place compared to a group of undergraduate students rather than a variation in the preferred styles of individuals. Master's students are generally more prone to scientific and research work that, in turn, forms a tendency to reflection and synthesis and activates various channels of perception of information, enhancing the role of reflective, intuitive and verbal styles. At the same time, no fundamental changes in learning styles are observed for individuals; their preferences remain typical for students of engineering and chemical specialities. The comparison of the learning profiles of the 3rd year students, entering the university after either secondary schools or medical colleges, provides additional arguments in favour of the importance of a selection stage in the formation of the profile of student groups. The former college students retain the preferences which have already been formed in the process of their admission and training at medical colleges and are inherent in future physicians and pharmacists. In contrast, school-leavers demonstrate preferences typical for the speciality of industrial pharmacy.
\end{abstract}

KEYWORDS: Index of Learning Style by R. Felder and B. Soloman; industrial pharmacy speciality; chemical disciplines; learning style stability; college graduate and school-leaver.

\section{INTRODUCTION:}

The urgent problem of modern education is the creation and maintenance of conditions ensuring the efficient acquisition of knowledge in specific subject areas $^{1}$. One of the ways that enhance the efficiency of the educational process consists in the development of adaptive learning strategies that take into account the psychophysiological characteristics of students and thus assist individualisation of their training. In turn, a successful learning strategy requires the identification

$\begin{array}{ll}\text { Received on 21.08.2018 } & \text { Modified on 10.09.2018 } \\ \text { Accepted on 13.10.2018 } & \text { C RJPT All right reserved }\end{array}$

Research J. Pharm. and Tech 2018; 11(10): 4277-4284.

DOI: 10.5958/0974-360X.2018.00784.9 
of predominant styles of learning of students, as well as the provision of consistency between learning and teaching styles ${ }^{2}$.

A learning style can be defined as a cognitive, psychological and emotional behaviour which is typical for a student and serves as a relatively stable identifier of how a person interacts with the learning environment. Such a definition takes into consideration the fact that a preferred learning style is an adaptive strategic response to a situation. On the one hand, it depends on different factors, such as e.g. level of interest. On the other hand, a learning style shows its worth as a more stable feature associated with personal characteristics. A variety of approaches are used to characterise the learning styles of people ${ }^{3,4}$. Each of them has advantages and disadvantages while there is no generally accepted universal theory. However, among the existing developments, it is possible to highlight the common features which allow ones to identify the most critical differences in student's learning preferences, and establish a relationship between the degree of their manifestation and the effectiveness of learning specific subject areas.

Students from different areas of study often demonstrate different preferences in their learning styles $^{5-7}$. The origin of varying learning preferences in different environments is still under discussion. As mentioned above, learning styles are constituents of educational strategies that describe the actions of an individual in response to demands by a particular learning situation. Therefore, the learning styles are directly influenced by the educational technology used, including the types of educational resources, teaching methods, positions of teachers and educational institution, etc. ${ }^{2,3}$. In turn, individual peculiarities of scholarly activity are formed under the influence of cognitive styles of a person, such as coding and information processing methods, setting and solving of problems, cognitive attitudes to the environment, etc.

Connections between the learning styles and the academic performance of students are somewhat complicated $^{8-12}$. On the one part, if teachers understand students' preferences in learning styles, then they can design the course materials in accordance with them. On the other part, if students recognise their preferred methods of study, they can develop an optimal strategy for mastering the discipline in line with their wishes. In-depth research in this area is vital for implementing modern information and communication technologies (ICTs) into the teaching process which is the mainstream of contemporary education ${ }^{13,14}$. As is known ${ }^{15-17}$, the use of ICT-based electronic learning resources (eresources) does not automatically improve the quality of digestion of knowledge. E-resources are sensitive to a variety of characteristics of a person, including cognitive and learning styles, as was demonstrated in a few papers devoted to the use of e-resources in chemistry teaching ${ }^{18,19}$.

Today, ICT-based means are increasingly used in the training of future pharmacists ${ }^{20,21}$, while little information is known about students' learning preferences $^{22-24}$. Such a gap in knowledge requires additional research because understanding students' learning styles and developing appropriate teaching technologies will allow ones to optimise a set of eresources for the training of future pharmacists and thus provide the effectiveness of the ICT-based learning. The aim of this work is an experimental study of the learning preferences inherent in students of pharmaceutical specialities of different years of training.

\section{METHODS:}

Totally 188 students (Table 1) of the Faculty of Chemical and Biopharmaceutical Technologies took part in the survey at Kyiv National University of Technologies and Design (KNUTD) during 20172018 years. All they are learning by the speciality "Industrial Pharmacy" to get diploma qualification "Technician-Technologist" on the completion of the four-years undergraduate course or "Pharmaceutical Technologies" with diploma qualification "Master of Industrial Pharmacy" (one-year graduate course upon completion of Bachelor's Degree).

Table 1: Number of students participated in the survey
\begin{tabular}{|l|l|l|l|}
\hline Speciality & Year & $\begin{array}{l}\text { Total number of } \\
\text { students }\end{array}$ & $\begin{array}{l}\text { Including } \\
\text { college } \\
\text { graduates }\end{array}$ \\
\hline Industrial pharmacy & 1 & 28 & \\
\hline Industrial pharmacy & 2 & 41 & 4 \\
\hline Industrial pharmacy & 3 & 58 & 10 \\
\hline Industrial pharmacy & 4 & 47 & \\
\hline Industrial pharmacy & 5 & 14 & \\
\hline & Total & $\mathbf{1 8 8}$ & \\
\hline
\end{tabular}

Most students entered KNUTD after graduating from secondary schools. A smaller part of 2nd- and 3rdyear students first graduated from various medical colleges, and then they enrolled for a baccalaureate course at KNUTD, starting directly from the second or third year of study. Taking into account the different backgrounds of school and college graduates, in some cases, the characteristics of former college students were analysed separately. Then the results of former college students were compared with the results of former secondary school-leavers. 
All students participated in the survey to identify their preferred learning styles with the use of Index of Learning Style (ILS) instrument developed by R. Felder and B. Soloman (thereinafter Felder-Soloman's model $)^{25}$. The model includes interviewing respondents and analysing their answers to 44 questions to assess preferences on four complementary dimensions. A pair of style / antistyle characterises each dimension. All dimensions and a list of the available styles with their brief description are shown in Table 2.

Table 2: Learning styles and dimensions of Felder-Soloman's model

\begin{tabular}{|l|l|l|}
\hline Dimension & $\begin{array}{l}\text { Style name } \\
\text { (in short) }\end{array}$ & Description \\
\hline $\begin{array}{l}\text { Perception of } \\
\text { information }\end{array}$ & $\begin{array}{l}\text { Sensitive } \\
\text { (sen) }\end{array}$ & Awareness of information, facts \\
\cline { 2 - 3 } & Intuitive (int) & $\begin{array}{l}\text { Intuition, forming an abstract } \\
\text { concept }\end{array}$ \\
\hline $\begin{array}{l}\text { Sensors for } \\
\text { perception }\end{array}$ & Visual (vis) & $\begin{array}{l}\text { Preference to drawings and } \\
\text { diagrams }\end{array}$ \\
\cline { 2 - 3 } & Verbal (vrb) & $\begin{array}{l}\text { Preference to the written or oral } \\
\text { explanation }\end{array}$ \\
\hline \multirow{2}{*}{$\begin{array}{l}\text { Understanding } \\
\text { information }\end{array}$} & Active (act) & Activity, experimentation \\
\cline { 2 - 3 } & $\begin{array}{l}\text { Reflective } \\
\text { (ref) }\end{array}$ & Reflections, observations \\
\hline \multirow{2}{*}{$\begin{array}{l}\text { Learning } \\
\text { patterns }\end{array}$} & $\begin{array}{l}\text { Sequential } \\
\text { (seq) }\end{array}$ & $\begin{array}{l}\text { Step-by-step understanding, } \\
\text { convergent thinking and analysis }\end{array}$ \\
\cline { 2 - 3 } & Global (glo) & $\begin{array}{l}\text { Understanding by jumps, system } \\
\text { thinking and synthesis }\end{array}$ \\
\hline
\end{tabular}

Indices of Learning Style categorise individuals' choices regarding mode and type of percept of information, approaches for the information processing and the progress rate towards understanding. Learning styles are calculated for a scale from 0 to 11 points; the total score for each of the four available dimensions is 11 points. Since the overall style and anti-style score is always 11 points, the result for only one style for each of the four aspects is sufficient to get a general picture.

The advantage of one of two opposite styles was determined in two ways. For the first (bipolar) option, the advantage of a particular style was attributed to all answers with 6-11 points, and its absence to $0-5$ points. Then the total and relative numbers of respondents of a specific preferred style were calculated. The relative numbers in percentage were used to describe preferred learning styles in different groups of students. This method was used to plot learning profiles of student groups and compare profiles in different groups from various universities and areas of study.

The second way for learning preference description is based on the distribution of 11 points between two opposite styles. The points in the range 4-7 are considered as a sign of balance between styles, 8-9 points in favour of one style indicate its moderate advantage, and 10-11 points prove the presence of a strong advantage. The second method was used to study correlations and links between preferred learning styled and academic performance of students.

The results of the study of learning preferences of students were compared with the results of academic performance in learning chemistry and chemical technology disciplines, such as inorganic, organic, analytical, physical and colloid, and biopharmaceutical chemistry; pharmacognosy; pharmaceutical technology and chemical technology apparatus. In total, the results of examinations in 8 disciplines, which are taught in the baccalaureate and scored on a 100-point scale, were analysed for student groups with different learning profiles.

The experimental results obtained were analysed by statistical methods using IBM SPSS-19 software. Any correlations between individual data were examined with the use of Pearson's correlation coefficients. All data were tested for variance homogeneity with the Levene's test and normal distribution with the ShapiroWilks model. The results were presented either as the means with standard errors of the mean for data with a normal distribution or medians and quartiles for asymmetric distributions.

One-way analysis of variance (ANOVA) was used to analyse possible differences among the mean values. The significance level $\alpha$ was fixed at or below 5\% ( $\alpha \leq$ 0.05). Post hoc pairwise multiple comparisons were applied if the means display the significant differences, Post hoc tests allow one to determine which means differ. The least significant difference for equal variances or Tamhane's T2 methods for unequal variances were used in post hoc comparisons depending on the results of Levene's tests.

\section{RESULTS:}

Available learning profiles for the 1st- to 5th-year students are shown in Fig. 1 compared to the mean profile averaged over all five years of study. Significant changes in the learning profiles do not occur during the baccalaureate studies (Fig. 1, a, b, c, d). Students are mainly characterized by active (65-79\% of all students), sensitive (82-92\%), visual (75-81\%) and sequential (64-73\%) styles. The mean figures for all students are respectively $71 \%, 88 \%$. $77 \%$ and $70 \%$; the difference between current and mean indices does not usually exceed $1-5 \%$ (1-8\% for dimension act-ref). 

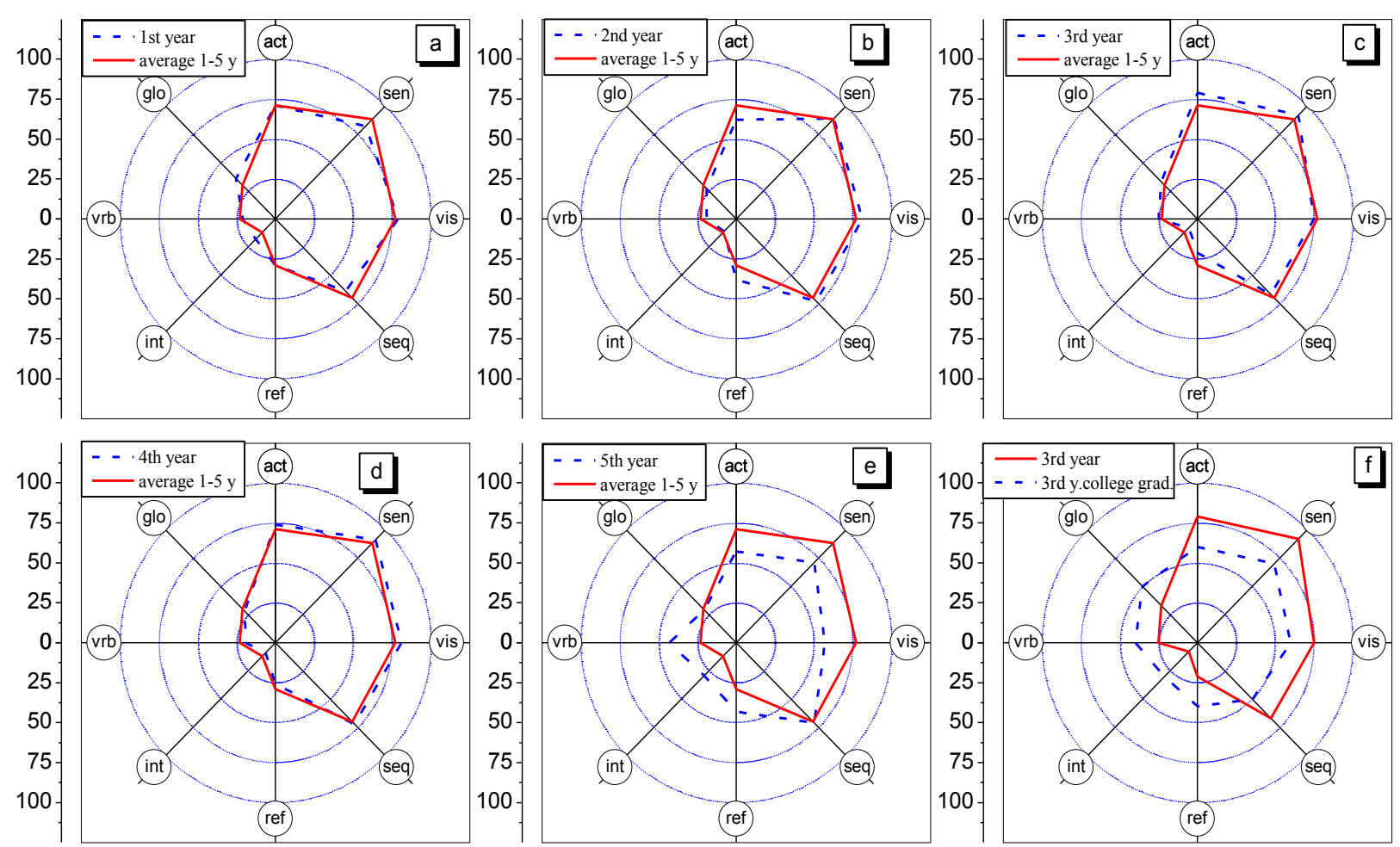

Fig. 1: Learning profiles of industrial pharmacy students of different years of study at KNUTD

A significant quantitative difference in educational preferences (Fig. 1e) appears in the 5th year of study. However, no wide qualitative discrepancy is observed: all students remain mostly active, sensitive, visual and sequential. Nevertheless, master's students are more reflective, verbal and intuitive compared to undergraduate students. No significant changes occur in glo-seq dimension. The differences between the average and the 5 th year figures are between $14 \%$ and $20 \%$ for three aspects and within $2 \%$ for the fourth one (glo-seq).

Figure 1f compares the learning preferences of 3rd-year students who have entered the university after either secondary schools or medical colleges, respectively. Former college students look much more balanced: the values of their preferences do not usually exceed 60$70 \%$, and the number of students divides in half for gloseq dimension.

The issue of availability of any relationships between the learning styles and academic performance is of importance for the optimal design of curricula. The results of the survey, where actual learning style of each student was attributed by a particular score on an 11point scale, were compared with the individual results of examinations in 8 chemistry and chemical technology disciplines, assessed by a 100-point scale. Such correlations seem to be quite complicated if any. The analysis of Pearson's pair correlations found no statistically significant interdependences between the examination points and learning preferences for individual students. The Pearson's correlation coefficients do not exceed $\pm 0.05-0.15$ values.

However, some differences in the examination scores are observed among different groups of students. As seen from Fig. 1, the typical profile of future pharmacists is based on the preferences towards the following four styles: act, sen, vis and seq. Students with such preferences can be conventionally referred to as typical and grouped into a group of typical students. Using the bipolar method for classification, totally 47 persons among 105 students of the 3rd- and 4th-years of study can be ascribed to students with typical profiles. Other individuals, which demonstrate at least one preferred style different from the four typical styles mentioned above, were made up of a group of others (58 students).

The analysis of histograms examination points indicates their proximity to the normal (Gaussian) shape in both groups. Such a statement is illustrated in Fig. 2 where the results of examinations in pharmacognosy are shown. Therefore, the mean values together with the mean errors are possible to use for the description of the characteristics of groups and a comparison of the academic performances of different student groups using ANOVA. 


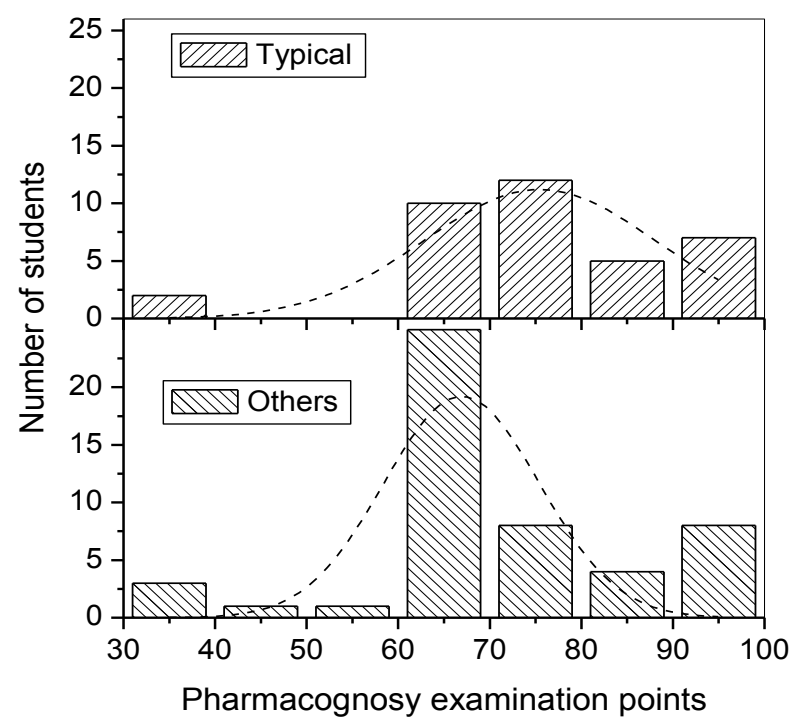

Comparison of the points obtained in chemical discipline examinations is presented in Fig. 3a for both groups. As is seen, students with typical learning profiles consistently show better learning outcomes. The only exception is the result in analytical chemistry where the performance of both groups is practically equal. According to the statistical analysis (ANOVA), the revealed differences in scores are not statistically significant. Nevertheless, they are observed in virtually all considered cases.

Fig. 2: Distribution of the results of examinations in pharmacognosy for two groups of 3rd- and 4th-years students with different profiles of learning preferences

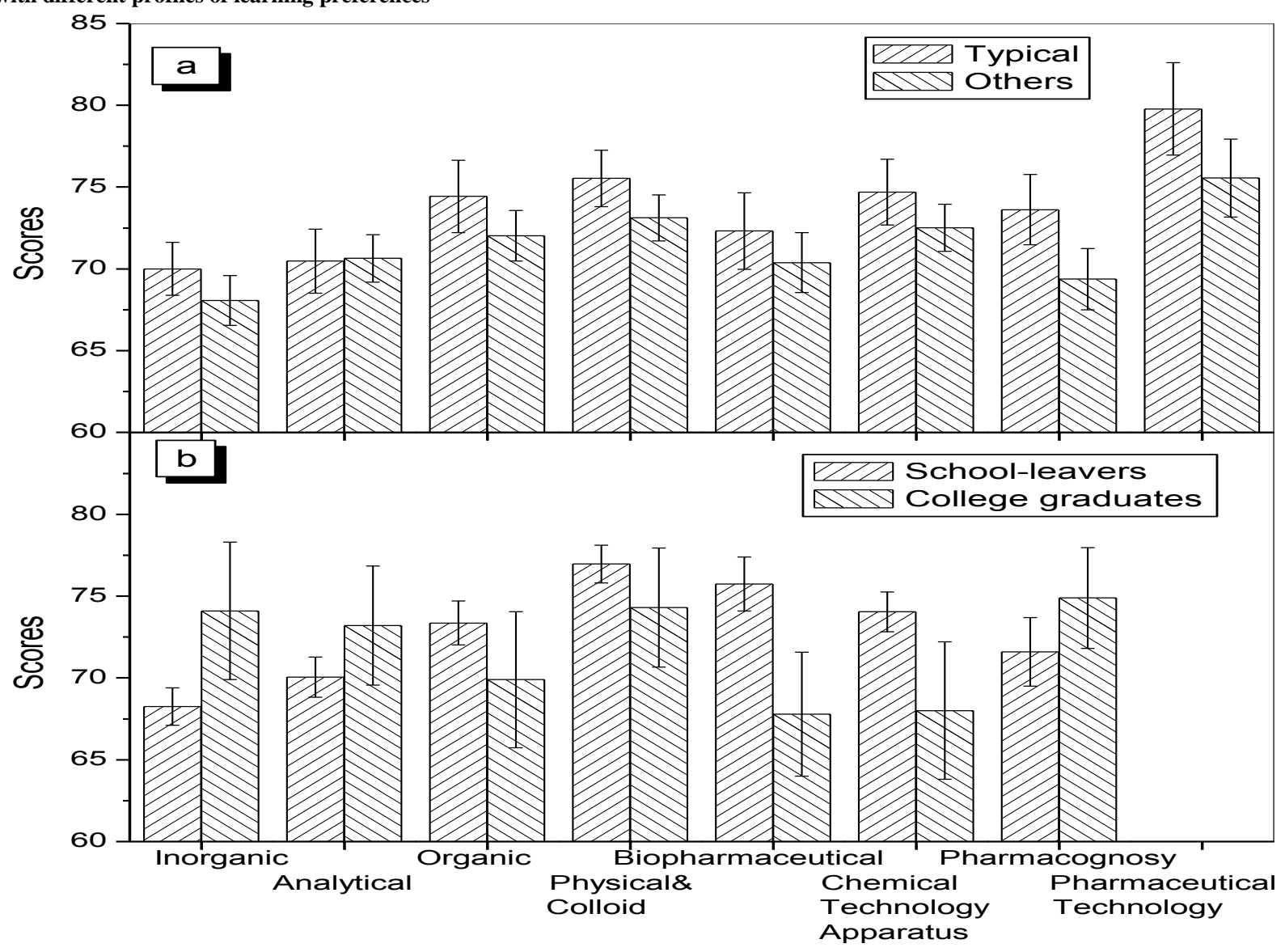

\section{Chemical disciplines}

Fig. 3: The difference between the average examination points scored by students of the $3^{\text {rd }}$ and $4^{\text {th }}$ years: a $-\mathrm{a}$ group with typical learning profiles in comparison with a group of other students; $b$ - a group of medical college graduated in contrast with a group of secondary school-leavers 
Similar to Fig. 3a figures are shown in Fig. 3b for two groups of students consisted of school-leavers and graduates of medical colleges. The values of differences in scores are not sufficient to form a statistically significant difference except for the results for biopharmaceutical chemistry. The results of examinations look mixed at first glance. For some subjects, such as inorganic and analytical chemistry, and pharmacognosy, college graduates demonstrate better academic performance, but for other subjects, they yield to school-leavers.

\section{DISCUSSION:}

The results obtained regarding the relative number of students with different learning preferences (Fig. 1, a, b, c) indicate that the learning styles remain relatively stable during undergraduate studies. A dominating number of students (over 80\%) show preference to visual and sensitive styles, and a significant amount of students (more than 60\%) prefer active and sequential style.

At the same time, the learning preferences of master's students differ significantly from those of university undergraduates (Fig. 1e). In our opinion, such a difference gives no evidence to the instability of the acquired preferences but illustrates the impact of an additional selection phase that takes place in the course of formation of groups of master's students. Students, who plan to do research work or teach at universities, usually come to a master's course. Such students are prone to reflection, generalisation and the formation of abstract concepts. In this context, their learning preferences seem to be close to those of natural sciences teachers. For example, the learning profiles of faculty members, who teach chemistry, are distinguished by higher indexes of styles ref, int and glo (i.e. in three dimensions of four) compared to students of the speciality chemistry ${ }^{26}$. In the aspect of vis-vrb, the profiles of teachers and students differ little from each other. The patterns of master's students are changing towards teachers' patterns: the relative number of master's students with ref and int styles increases. Research in this area should be continued to make profound conclusions. Nevertheless, the results obtained indicate the relative stability of the learning styles. At the same time, people with particular learning preferences are subconsciously inclined to choose the kind and area of educational activity which combine well with their preferences.

At first glance, the unexpected result consists in a significant discrepancy in the learning profiles between third-year students who came from secondary schools and medical colleges (Fig. 1f). The first group of students exhibits a typical pharmacist profile which is close to profiles of technology and natural science students $^{6}$. The latter is more reflective, intuitive, global and verbal. Therefore, college graduates demonstrate substantially different preferences in all four dimensions and are generally more balanced compared to schoolleavers.

As in the previous case, the invented difference is caused by different ways of student selection and is not in rapid changes of relatively stable styles. Such a conclusion is lustrated in Fig. 4 where predominant learning profiles of KNUTD students graduated either from schools or colleges are compared with those of medical students ${ }^{27}$ and pharmaceutical students 28,29 from medical universities in the world.

The smallest difference concerns the dimension of vis$v r b$, where a preference for the visual style is typical for all areas of study. For act-ref and sen-int dimensions, students KNUTD graduated from schools demonstrate learning profiles which are close to the profiles of students of technological specialities ${ }^{2,6}$. They have a pronounced preference for styles act and sen, while medical students with strong reflectivity and intuitiveness are located at the opposite pole. The characteristics of college graduates studied at KNUTD are situated between these poles and next to the figures of future pharmacists from world medical universities. For glo-seq dimension, the results of college graduates are also located in the middle zone between the most sequential school-leavers and foreign pharmacists and the most global future physicians.

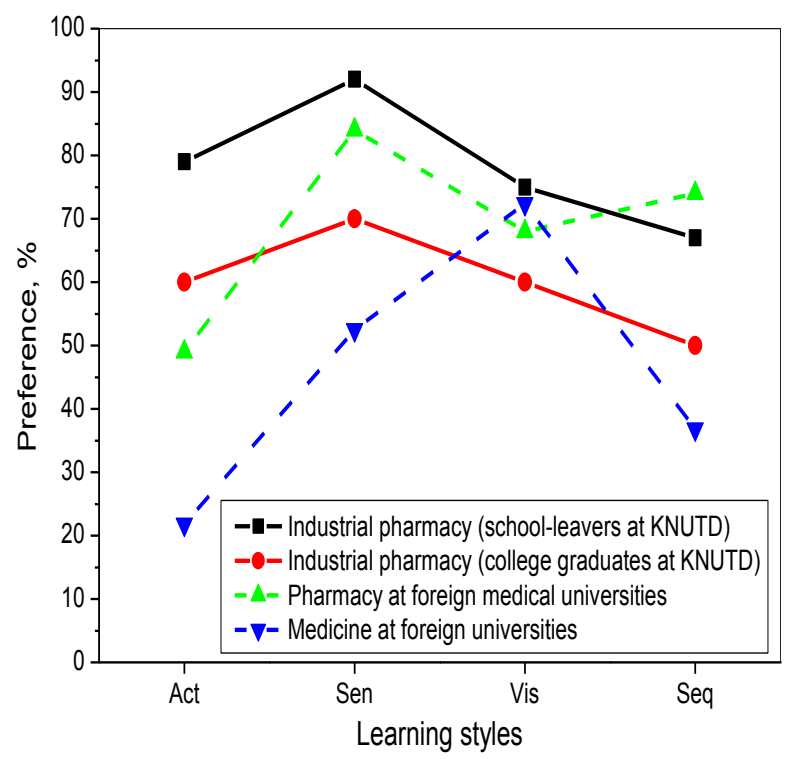

Fig. 4: Learning styles of industrial pharmacy students at KNUTD in comparison with those of pharmaceutical ${ }^{28,29}$ and medical students ${ }^{27}$ at foreign medical universities 
Thus, future technologists of the pharmaceutical industry, who entered KNUTD after graduating from secondary schools, and medical students demonstrate the most distant and different learning preferences in three of four dimensions. And in virtually all cases, the future technologists, pre-graduated from medical colleges, are located between these poles that bring them closer to the profiles of students of pharmaceutical faculties of medical universities. In our view, all these observations do not contradict the idea that under conditions of the relative stability of learning styles of individuals, the selection of students for admission to a university or a master's course is the primary factor forming the learning profile of student groups.

The learning styles typical for pharmacists are the educational preferences of a majority, but not all students. If we switch from the bipolar model of determination of learning styles and take into account the degree of each preference (the score of 4-7 points is attributed to a balanced style), then not all students belonging to the aforementioned majority simultaneously have four pronounced preferences with a score of 8-11 points in the dimensions of act, sen, vis and seq.

The relative numbers of students having 0 or are entirely balanced, 1, 2, 3 or 4 preferred learning styles are shown in Fig. 5. About $90 \%$ of respondents come from students with 1-3 dominant styles. The number of possible combinations of styles in all these cases is huge that significantly complicates the analysis of data, including the study of correlations between styles and academic performance. Most likely, this precludes the establishment of any relationships between the characteristics of individual styles and the results of examinations.

A variety of the learning profiles of individual students raises questions about optimal approaches to teaching students with non-typical learning preferences. The teaching of chemical disciplines in the modern world occurs with the widespread use of ICT means. As shown $\mathrm{in}^{30-32}$, the attitude to different means of ICT, as well as the efficiency of their application is dependent on the actual learning preferences. Therefore, to ensure the high quality of teaching of all students, optimisation of pedagogical approaches and means of ICT is necessary for accordance with the available learning preferences of all students. Possible technologies of such optimisation were proposed in some works ${ }^{33,34}$.

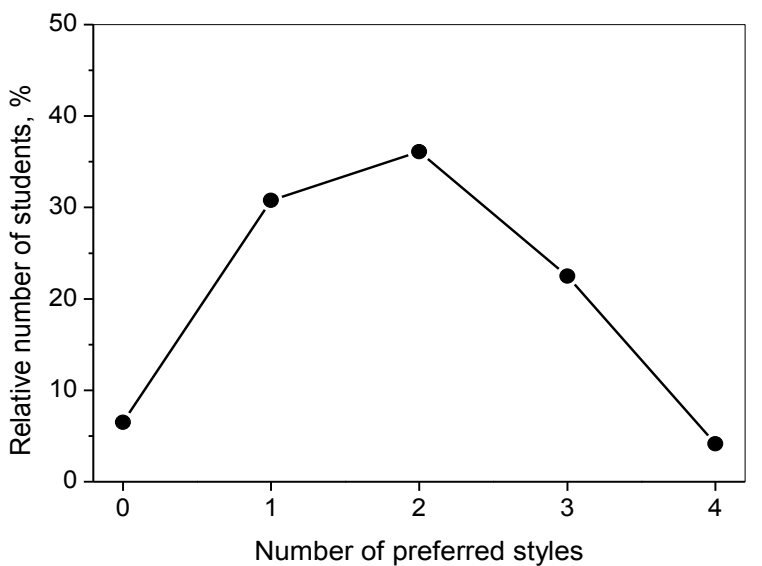

Fig. 5: The relative number of students of KNUTD as a function of the number of learning preferences

The preliminary analysis of the results of teaching chemical disciplines (Fig. 3) shows that the quality of educating students with typical profiles is usually higher than others, although this difference often is small and statistically insignificant. It is most likely that the pedagogical approaches and learning resources used are better optimised for students with typical learning profiles. On the other hand, they may cause complications for students with other, non-typical learning preferences. It is evident that the conclusion drawn is preliminary and requires further research in this direction.

\section{CONCLUSIONS:}

A majority of baccalaureate students, which are future technologists of the pharmaceutical industry, are characterised by active (65-79\% of all respondents), sensitive (82-92\%), visual (75-81\%) and sequential (64$73 \%$ ) learning styles. During four years of studies, the formed preferences in learning styles are practically unchanged, indicating their relative stability.

Master's students of the same speciality differ significantly from undergraduate students, demonstrating more reflective, verbal and intuitive learning styles. No significant difference is observed in global-sequential dimension. The observed difference in learning styles between groups of undergraduate and graduate students is most likely formed at a stage of the additional selection of students when they join the master's course. This hypothesis is confirmed by the fact that the learning preferences of students, who graduated from medical colleges, differ significantly from the profiles of students enrolled in the university after secondary schools. Graduates of medical colleges, in their learning preferences, are in many ways closer to students who study pharmacy or medicine at medical universities. 
Academic performance of students with the typical learning profile, which was assessed on the base of the results of examinations in eight chemistry and chemical technology disciplines, is usually better than that of students with other or non-typical profiles. The pedagogical approaches and resources used in chemistry teaching are mainly oriented towards students with typical learning profiles. As a result, the curriculum in chemistry and related disciplines is better apprehended by these students. At the same time, such a fact accentuates the problem of improving the adaptation of teaching with due account for the needs of students with other learning preferences.

\section{ACKNOWLEDGEMENT:}

The author would like to thank Ms Ya. Mikhalko for assistance in conducting the survey.

\section{CONFLICT OF INTEREST:}

The authors declare no conflict of interests.

\section{REFERENCES:}

1. Shewale BD, Patil PO, Kosalge SB, Fursule RA, Sapkal NP. Quality Education in Pharmacy: Need of $21^{\text {st }}$ Century. Research Journal of Pharmacy and Technology. 2009; 2(4): 648-652.

2. Derkach TM. Theoretical and Methodological Basics of Training of Future Specialists of Chemical Specialties by Means of Information Technologies. Dnipro, Ukraine: ART-Press, 2013

3. Velusamy B, Anouncia SM. A narrative review of research on learning styles and cognitive strategies. Journal of Theoretical and Applied Information Technology. 2013; 52(1): 23-29.

4. Coffield F, Moseley D, Hall E, Ecclestone K. Learning styles and pedagogy in post-16 learning A systematic and critical review. The Learning and Skills Research Centre, London, UK. 2004.

5. Derkach T, Starova T. Preferred learning styles of students of natural field of study. Science and Education. 2017; No6: 51-56. doi: https://doi.org/10.24195/2414-4665-2017-6-8

6. Derkach T. Preferred learning styles for students majoring in chemistry, pharmacy, technology and design. Advanced Education. 2018; No9: 55-61. DOI: 10.20535/2410-8286.131078

7. Yaroshenko OG, Derkach TM. Comparative analysis of learning styles for students of different specialities. Pedagogika i Psykhologia. 2012; No1: 43-47. (in Ukrainian)

8. Chun Lok KL, Kuan CT. Personality, Learning Styles, Learning Motivation and Academic Performance: A Study of Macau Business Undergraduates in a Microeconomics Course. European Journal of Business and Management. 2016; 8(21): 130-139.

9. Cetin B. Predicting academic success from academic motivation and learning approaches in classroom teaching students. Contemporary Issues in Education Research, (2015); 8(3): 171-180.

10. Ishak N, Awang MM. The relationship of student learning styles and achievement in history subject. The International Journal of Social Sciences and Humanities Invention. 2017; 4(3); 3372-3377.

11. Surjono HD. The effects of multimedia and learning style on student achievement in online electronics course. Turkish Online Journal of Educational Technology. 2015; 14(1): 116-122.

12. Wilson K, Narayan A. Relationships among individual task selfefficacy, self-regulated learning strategy use and academic performance in a computer-supported collaborative learning environment. Educational Psychology. 2016; 36(2): 236-253.

13. Neeti R, Yogendra J. Education through ICT Technology: Need of an hour. Asian Journal of Management. 2014; 5(2): 246-249.

14. Gautam RK, Bhambu AK, Rai S, Sahu D. Pharmacy in light of Information and Technology: An Overview. Research Journal of Pharmacy and Technology. 2013; 6(1): 51-57.

15. Margaret SFX, Blessed WA, Kumar A, Das S, Sen S, Ranjalkar J, Sukumaran D. Evaluation of Efficacy of Tutorials in Pharmacology for 2nd year undergraduate Medical Students in India. Research Journal of Pharmacy and Technology. 2016; 9(2): 153-156.
16. Pulla Divya Sree, Ashok Kumar M, Palani Shanmugasundaram. Accessibility of Computer and Knowledge among Pharmacy Students at a Private University of Tamilnadu. Research Journal of Pharmacy and Technology. 2017; 10(1): 188-192. DOI: 10.5958/0974360X.2017.00041.5

17. Sharma A, Amarnath S, Jaikumar S, Basalingappa S, Ramaswamy S, Thulasimani M. Assessment of Knowledge about Pharmacovigilance among Medical Students in Puducherry. Research Journal of Pharmacy and Technology 2014; 7(4): 447-449.

18. Derkach TM. Application of ICT-based Learning Resources for University Inorganic Chemistry Course Training. European Researcher. 2013; 44(3-2): 649-653.

19. Derkach TM. Electronic resources in teaching basic chemical disciplines at universities. Science and Education. 2016; No12: 99109.

20. Naha A, Girish Pai K, Nayak UY, Reddy MS, Koteshwara KB, Udupa N. Implementation of Task based learning for overall development of pharmacy students. Research Journal of Pharmacy and Technology 2012; 5(2): 291-294.

21. Naik A, Sangle D. Comparative Study of Case Based Learning (CBL) with Didactic Lectures as a Teaching-Learning (T-L) Method for Improvement of Ethical Skills of M.Sc. Pharmaceutical Medicine Students. Research Journal of Pharmacy and Technology. 2013; 6(8): 912-915.

22. Amarnath S, Sharma A, Basalingappa S, Jaikumar S, Ramaswamy S, Thulasimani M. A Survey on the Preference of Text Book of Pharmacology by Undergraduate Medical Students in a Medical College in Puducherry. Research Journal of Pharmacy and Technology. 2015; 8(1): 31-34. DOI: 10.5958/0974360X.2015.00006.2

23. Geethika B, Karpagam K. Comparing the choice of Ebooks Vs Textbooks among dental students- A Questionnaire-based study. Research Journal of Pharmacy and Technology. 2016; 9(8):1077-1078. DOI: 10.5958/0974-360X.2016.00204.3

24. Alrakaf I, Sainsbury E, Smith L. First year Undergraduate Pharmacy Students' and Academics' views of and Preferences for Learning \& Teaching. A Preliminary Investigation. Research Journal of Pharmacy and Technology. 2014; 7(2): 161-167.

25. Felder RM, Soloman BA. Index of Learning Styles. 1997. Available from http://www4.ncsu.edu/felderpublic/ILSpage.html (accessed 01.07.18)

26. Derkach TM. The consistency of learning preferences of students and teachers of different areas of training. Naukovi Zapysky: Zb. nauk. statei NPU im. M.P. Drahomanova. K.: Vyd-vo NPU im. M.P. Drahomanova. 2011; No99: 42-52. (in Ukrainian)

27. Hughes JM, Fallis DW, Peel JL, Murchison DF. Learning Styles of Orthodontic Residents. Journal of Dental Education. 2009; No3: 319327.

28. Laight DW. Attitudes to concept maps as a teaching/learning activity in undergraduate health professional education: influence of preferred learning style. Medical Teacher. 2004; 26(3): 229-233. https://doi.org/10.1080/0142159042000192064

29. Teevan CJ, Li M, Schlesselman LS. Index of Learning Styles in a U.S School of Pharmacy. Pharmacy Practice. 2011; 9(2): 82-87.

30. Derkach TM. Perception of e-learning resources by students with different learning styles. Naukovi Zapysky: Zb. nauk. statei NPU im. M.P. Drahomanova. K.: Vyd-vo NPU im. M.P. Drahomanova. 2012; No100: 87-97. (in Ukrainian)

31. Derkach TM. Cognitive load measurement within the research of efficient usage of learning software. Information Technologies and Learning Tools. 2011; 22(2). Retrieved from http://journal.iitta.gov.ua/index.php/ itlt/issue/view/41 (in Ukrainian) (accessed 01.07.18)

32. Derkach TM. Prevention of students' cognitive overload in the course of learning with the use of electronic resources. Information Technologies and Learning Tools. 2012; 29(3). Retrieved from http://journal.iitta.gov.ua/index.php/ itlt/issue/view/41 (in Ukrainian) (accessed 01.07.18)

33. Derkach TM. Chemistry teaching by means of ICT-based resources with the regard for preferred learning styles of university students. Informational Technologies in Education. 2013; No14: 48-57.

34. Derkach TM. Information and communication technologies in teaching chemistry. In: Effective methods of using information and communication technologies in education, VP Maloy (ed). Krasnoyarsk, Russia: KGPU, TsNI “Monographia”. 2013: pp.141-162. 